\section{Exploring valrubicin's effect on Propionibacterium acnes-induced skin inflammation in vitro and in vivo}

\author{
Louise Rottboell,' Sarah de Foenss,' \\ Kenneth Thomsen, ${ }^{2}$ Helle Christiansen, ${ }^{1}$ \\ Stine M. Andersen, ${ }^{1}$ Tomas N. Dam, ${ }^{3}$ \\ Cecilia Rosada, ${ }^{1}$ Karin Stenderup ${ }^{1}$ \\ 'Department of Dermatology, Aarhus \\ University Hospital; ${ }^{2}$ Department of \\ Biomedicine, Aarhus University; \\ ${ }^{3}$ Department of Dermatology, Roskilde \\ Hospital, Denmark
}

\section{Abstract}

Acne is a common skin disease involving colonization with Propionibacterium acnes $(P$. acnes), hyperproliferation of the follicular epithelium and inflammatory events. Valrubicin is a second-generation anthracycline, non-toxic upon contact, and available in a topical formulation. Valrubicin's predecessor doxorubicin possesses antibacterial effects and previously we demonstrated that valrubicin inhibits keratinocyte proliferation and skin inflammation suggesting beneficial topical treatment of acne with valrubicin. This study aims to investigate valrubicin's possible use in acne treatment by testing valrubicin's antibacterial effects against $P$. acnes and $P$. acnes-induced skin inflammation in vitro and in vivo. Valrubicin was demonstrated not to possess antibacterial effects against $P$. acnes. Additionally, valrubicin was demonstrated not to reduce mRNA and protein expression levels of the inflammatory markers interleukin (IL)$1 \beta$, IL-8, and tumor necrosis factor (TNF)- $\alpha$ in vitro in human keratinocytes co-cultured with $P$. acnes. Moreover, in vivo, valrubicin, applied both topically and intra-dermally, was not able to reduce signs of inflammation in mouse ears intra-dermally injected with $P$. acnes. Taken together, this study does not support beneficial antibacterial and anti inflammatory effects of topical valrubicin treatment of acne.

\section{Introduction}

Acne vulgaris is one of the most common skin diseases worldwide affecting more than $85 \%$ of all adolescents. ${ }^{1}$ The disease presents a significant clinical problem with severe social and psychological implications. The pathogenesis of acne is multifactorial and usually impli- cates follicular colonization with the gram-positive anaerobe Propionibacterium acnes ( $P$. acnes) and inflammation upon manifestation. ${ }^{2,3} P$. acnes has previously been shown to stimulate secretion of pro-inflammatory cytokines such as interleukin (IL)-1 $\beta$, IL-8 and tumor necrosis factor (TNF)- $\alpha .{ }^{4}$ Current acne treatments present side effects such as skin irritation, bacterial resistance, teratogen effects, and chronicity rendering acne as a disease with persistent need for new and improved treatment modalities. ${ }^{1}$

Valrubicin (N-trifluoroacetyladriamycin-14valerate) is a second-generation anthracycline currently FDA-approved for intra-vesical treatment of bacillus Calmette-Guérin-refractory bladder cancer. ${ }^{5}$ Valrubicin is derived from doxorubicin, which exhibits both antibiotic and antineoplastic activities. ${ }^{5,6}$ Valrubicin excels by lacking contact and cardiac toxicity. ${ }^{6}$ Valrubicin's improved safety profile and excellent tissue penetration ${ }^{5,6}$ has led to the development of a cream formulation facilitating topical application and possible treatment of hyperproliferative skin diseases as demonstrated by alleviation of psoriasis and prevention of skin tumor development in mouse models; ${ }^{7,8}$ an effect ascribed to valrubicin's ability to inhibit keratinocyte proliferation and skin inflammation. ${ }^{7-9}$

In this study, we aim to investigate whether topical valrubicin treatment may play a future role in acne treatment, thus valrubicin's antibacterial effect against $P$. acnes is tested together with valrubicin's anti-inflammatory effect on $P$. acnes-induced inflammation in vitro and in vivo. Valrubicin did not demonstrate antibacterial effects nor did it reduce expression levels of IL$1 \beta$, IL- 8 , and TNF- $\alpha$, in vitro, or reduce signs of inflammation in vivo. In conclusion, this study does not support beneficial antibacterial and anti-inflammatory effects of topical valrubicin treatment of $P$. acnes-associated acne. The submitted manuscript includes primary normal human epidermal keratinocytes (NHEKs), isolated from healthy donors undergoing skin reductive surgery. All donors have signed a donor consent letter and the project is approved by the regional ethical committee (Den videnskabsetiske Komité for Århus Amt) with journal number 20030125. The submitted manuscript also includes animal experimentation which is approved by the Danish Animal Experiments Inspectorate (Dyreforsøgstilsynet) with journal number 2011/561-1958.

\section{Materials and Methods}

\section{P. acnes bacteria}

Three different $P$. acnes strains: 1.4.L1, 12.1.L1 and 30.2.L1, were included in this
Correspondence: Karin Stenderup, Research Centre S., Department of Dermatology, Aarhus University Hospital, P.P. Oerumsgade 11, bldg. 15b, DK-8000 Aarhus C, Denmark.

Phone: +45.7846 .1838 - Fax: +45.7846 .1850 .

E-mail: karin.stenderup@clin.au.dk

Key words: Propionibacterium acnes; valrubicin acne; skin inflammation; mouse model.

Acknowledgements: the authors thank Annette Blak Rasmussen, Winnie Heidemann and Tove Findahl for their excellent technical assistance, Lars Iversen and Mogens Kilian for making available laboratory facilities, and Mogens Kilian and Holger Brüggemann for guidance. We thank Elisabeth de Darkó from Valderm ApS for supplying valrubicin.

Contributions: LR, TND, CR, KS, conception of the work; LR, SdF, KT, HC, SMA, acquisition of data for the work; LR, TND, CR, KS, analysis and interpretation of data for the work; LR, SdF, KT, HC, SMA, TND, CR, KS, drafting the work and critically revising it for important intellectual content and final approval of the manuscript version to be published.

Conflict of interest: LR, SdF, KT, HC, SMA, CR, declare no conflict of interest; KS received funding for operating expenses from Valderm ApS; TND is a consultant at Valderm ApS.

Funding: this work was financially supported by Valderm ApS; Institute of Clinical Medicine, Aarhus University; Aage Bang's Foundation.

Received for publication: 19 October 2015.

Accepted for publication: 29 November 2015.

This work is licensed under a Creative Commons Attribution NonCommercial 3.0 License (CC BYNC 3.0).

(C) Copyright L. Rottboell et al., 2015

Licensee PAGEPress, Italy

Dermatology Reports 2015; 7:6246

doi:10.4081/dr.2015.6246

study. 1.4.L1 and 12.1.L1 are sequence type (ST)18 and strongly associated with moderate to severe acne while 30.2.L1 is ST27 and associated with healthy skin. Strains were kindly provided by Professor Mogens Kilian, Institute of Biomedicine, Aarhus University, Denmark, and isolated from acne patients as previously described. ${ }^{10-12} P$. acnes were inoculated on 5\% blood agar or reinforced clostridium agar and incubated under anaerobic conditions at $37^{\circ} \mathrm{C}$. Further growth was accomplished by inoculation on dialysis membranes (3500 Dalton, 3 Spectra/Por ${ }^{\circledR} \quad$ no.: 132725 , Spectrum Laboratories, Breda, the Netherlands) on $5 \%$ blood agar for four days or by re-suspension in brain heart infusion broth until reaching log phase growth. Bacteria were harvested, washed and re-suspended in isotonic saline water and used immediately. 


\section{Antibacterial assay}

TYEG agar supplemented with $2 \mu \mathrm{g} / \mathrm{mL}$ of furazolidone to inhibit growth of staphylococci, ${ }^{13}$ was used to test the antibacterial activity of valrubicin against $P$. acnes. Valrubicin in different concentrations and formulations were loaded onto sterile filter discs and placed on the surface of inoculated agar plates. Valrubicin $250 \mathrm{mg} / \mathrm{mL}$ in acetone (kindly provided by Valderm ApS, Lyngby, Denmark), 25 $\mathrm{mg} / \mathrm{mL}$ in acetone/DMSO [1:10], $5 \mu \mathrm{g} / \mathrm{mL}$ in acetone/sterile water $[1: 10,000], 40 \mathrm{mg} / \mathrm{mL}$ (Valstar®) in cremophor/ethanol [1:1], (kindly provided by Valderm ApS), $10 \mathrm{mg} / \mathrm{mL}$ (Valstar®) in cremophor/ethanol/sterile water [1:1:4], $10 \mathrm{mg} / \mathrm{mL}$ in cream (1\% batch 7077/001, kindly provided by Valderm ApS), 10 $\mathrm{mg} / \mathrm{mL}$ in cream gel (1\% batch $7078 / 001$, kindly provided by Valderm $\mathrm{ApS}$ ) and the vehicles: acetone, acetone/DMSO [1:10], acetone/sterile water [1:10,000], Cremophor® L (C5135, Sigma-Aldrich, Broendby, Denmark)/ethanol [1:1], Cremophor ${ }^{\circledR}$ L (C5135, SigmaAldrich)/ethanol/sterile water [1:1:4], cream and gel vehicles (kindly provided by Valderm $\mathrm{ApS}$ ) were tested. Discs with penicillin (5 $\mu \mathrm{g}$, Roscolab Ltd., London, UK) were added as positive control. Plates were incubated under anaerobic conditions at $37^{\circ} \mathrm{C}$ for three days. Antibacterial potential was determined as growth inhibition of the bacterial layer.

\section{Keratinocyte cell cultures}

Primary normal human epidermal keratinocytes (NHEKs) were isolated from four healthy donors undergoing skin reductive surgery. Informed consent was obtained and the study was approved by the Central Ethical Committee and conducted in accordance with the Declaration of Helsinki protocols. NHEKs were grown in keratinocyte serum-free medium (K-SFM, Invitrogen) containing the supplements for keratinocyte growth (epidermal growth factor and pituitary extract; Invitrogen), at standard conditions $\left(37^{\circ} \mathrm{C}, 5 \%\right.$ $\mathrm{CO}_{2}$, and $90 \%$ humidity) as previously described. ${ }^{14} 24 \mathrm{hrs}$ prior to co-culturing NHEKs with $P$. acnes, medium was removed, cells washed in PBS (Invitrogen), and new medium without antibiotics added. $P$. acnes were resuspended in Dulbecco's Modified Eagle's Medium (DMEM, Invitrogen, Carlsbad, CA, USA) containing $10 \%$ FBS without antibiotics prior to co-culture. The $P$. acnes strain 1.4.L1, associated with acne, was used. In house, unpublished results, demonstrated that freshly prepared $P$. acnes, harvested in log phase growth, stimulated a greater inflammatory response compared with thawed $P$. acnes, thus freshly prepared $P$. acnes were used throughout the study.

The effect of valrubicin on $P$. acnes-induced expression levels of inflammatory cytokines in NHEKs was determined by assessing five dif- ferent treatment groups. Group 1 was not cocultured with $P$. acnes, and served as negative control. Groups 2, 3, and 4 were co-cultured with $P$. acnes (strain 1.4.L1, $10^{3}$ freshly prepared $P$. acnes/NHEK). 30 minutes post $P$. acnes challenge, group 3 and 4 were furthermore treated with valrubicin $(5.0 \mu \mathrm{g} / \mathrm{mL}$, diluted 1:5,000 in acetone) or vehicle (acetone diluted $1: 5,000)$. Group 5 was treated with valrubicin (5.0 $\mu \mathrm{g} / \mathrm{mL}$ diluted 1:5,000 in acetone) alone. Each treatment group was performed in triplicate from each of the four donors.

\section{Measurement of inflammatory cytokine mRNA and protein \\ expression levels}

To analyze mRNA expression levels, cells were harvested $2.5 \mathrm{hrs}$ post $P$. acnes co-culture ( $2 \mathrm{hrs}$ post valrubicin or vehicle treatment) by transferring cells to ice, washing in ice-cold PBS (Invitrogen) and adding RNA-lysis-buffer including $\beta$-mercaptoethanol (SV 96 Total RNA Isolation System, Promega, Madison, WI, USA). Lysed cell samples were stored at $-80^{\circ} \mathrm{C}$ until processed for RNA purification. RNA was isolated according to the SV Total RNA Isolation System vacuum protocol (Promega) and cDNA and quantitative real-time reverse transcription-polymerase chain reaction (PCR) was performed as previously described. ${ }^{9}$ Expression of IL-1 $\beta$, IL-8 and TNF- $\alpha$ was determined by TaqMan ${ }^{\circledR}$ Gene Expression Assays (Assay ID: IL-1 $\beta$ : Hs00174097_m1, IL-8: Hs00174103_m1, TNF- $\alpha$ : Hs01113624_g1, Applied Biosystems, San Francisco, CA, USA). RPLP0 was used as internal reference (Assay ID: RPLP0: Hs99999902_m1, Applied Biosystems). The expression of each gene was analyzed in triplicate. To analyze expression levels of secreted proteins, cell supernatants were removed 12.5 hrs post $P$. acnes stimulation (12 hrs post valrubicin or vehicle treatment), snap-frozen in liquid nitrogen and stored at $-80^{\circ} \mathrm{C}$ until processed in the enzymelinked immunosorbent assay (ELISA) as previously described by use of DuoSet ${ }^{\circledR}$ ELISA development kits (IL-1//LL-1F2: DY201, CXCL8/LL-8: DY208, and TNF- $\alpha$ : DY210; R\&D Systems, Abingdon, UK). ${ }^{9}$ The expression of each protein was analyzed in triplicate.

\section{P. acnes-induced ear inflammation mouse model \\ C57BL/6J female mice (6-10 weeks old)} (Taconic, Ry, Denmark) were housed under standard conditions with a $12 \mathrm{hrs}$ light/dark cycle and controlled temperature. Animals were fed a standard rodent laboratory diet and given water ad libitum. During intra-dermal injection of $P$. acnes, measurement of ear thickness, and topical and intra-dermal injection treatment with valrubicin or vehicle, mice were anaesthetized in isoflurane (2-3.75\%). At the end of the experiment, mice were sacrificed by cervical dislocation. Animal experiments were approved by The Danish Experimental Animal Inspectorate. Ear inflammation was induced in mouse ears by challenging ears with intra-dermal injections of 10 $\mu \mathrm{L}\left(6 \times 10^{7}\right)$ or $15 \mu \mathrm{L}\left(9 \times 10^{7}\right)$ freshly prepared $P$. acnes (strain 1.4.L1) re-suspended in isotonic saline water. No ear inflammation was observed in control mice intradermally injected with only isotonic saline water after $24 \mathrm{hrs}$ (data not shown). To test the effect of valrubicin as topical treatment a short term (1 day) and a long term ( 2 weeks) experiment was performed. Valrubicin $(10 \mu \mathrm{g} / \mu \mathrm{L}$ dissolved in acetone) and vehicle (acetone) was administered in a volume of $10 \mu \mathrm{L}$ per dorsal and $10 \mu \mathrm{L}$ per ventral surface of each ear. In the short term experiment mouse ears were treated once topically, 30 minutes post challenge, with valrubicin (group $1, \mathrm{n}=9$ ) or vehicle (acetone, group $2, \mathrm{n}=16)$ and ear thickness was measured before ( $0 \mathrm{hrs}$ ) and $24 \mathrm{hrs}$ after challenge. In the long-term experiment, mouse ears were divided into five groups where groups 1 and 2 , and groups 3 and 4 were challenged with $6 \times 10^{7}$ or $9 \times 10^{7}$ freshly prepared $P$. acnes, respectively. 30 minutes post challenge and daily hereafter throughout the study, ears were treated topically with valrubicin (group $1, \mathrm{n}=7$ and group $3, \mathrm{n}=8$ ) or vehicle (acetone, group $2, \mathrm{n}=4$ and group $4, \mathrm{n}=8$ ). As control, an additional group of mouse ears (group 5, n=8) was left unchallenged but treated daily with valrubicin throughout the study. To test the effect of intra-dermal valrubicin treatment, 2 weeks post challenge, mouse ears were treated daily for 3 days with intra-dermal injections of valrubicin (Valstar ${ }^{\circledR}, 10 \mu \mathrm{L}$, group $1, \mathrm{n}=12$ ) or vehicle (cremophor/ethanol [1:1], $10 \mu \mathrm{L}$, group 2, $\mathrm{n}=11$ ). As control, an additional group of challenged mouse ears were left untreated (group $3, \mathrm{n}=9$ ).

Ear thickness was measured by a Mitutoyo digimatic indicator (Mitutoyo, Kawasaki, Japan) prior to and at indicated time points after ear challenge.

\section{Statistics}

For statistical analysis the two-tailed Student's t-test was employed. $\mathrm{P}<0.05$ was considered significant.

\section{Results}

\section{Valrubicin's antibacterial effect against $P$. acnes}

Valrubicin's antibacterial effect against $P$. acnes was tested by employing different concentrations and formulations of valrubicin 
(Table 1). Three $P$. acnes strains: clinical isolates 1.4.L1, 12.1.L1, and 30.2.L1 were inoculated on agar plates but no signs of bacterial clearing were demonstrated.

\section{Valrubicin's effect on}

\section{$P$. acnes-induced inflammation in keratinocytes in vitro}

Valrubicin's effect on $P$. acnes-induced inflammation in keratinocytes in vitro was tested in NHEKs co-cultured with freshly prepared $P$. acnes. $P$. acnes only significantly induced an increase in the mRNA expression level of IL-1 $\beta$ (Figure 1a) but not IL-8 (Figure 1b) and TNF- $\alpha$ (Figure 1c). The observed increased mRNA expression level of IL-1 $\beta$ and the existing expression levels of IL- 8 and TNF$\alpha$ were not affected by valrubicin treatment $(\mathrm{P}=0.98$ for IL-1 $\beta, \quad \mathrm{P}=0.52$ for IL- 8 , and $\mathrm{P}=0.88$ for TNF- $\alpha$ ). $P$. acnes significantly increased protein expression levels of both IL-1 $\beta$ (Figure 1d), IL-8 (Figure 1e) and TNF- $\alpha$ (Figure 1f), however, valrubicin treatment was demonstrated not to reduce the $P$. acnes-induced expression levels of IL-1 $\beta \quad(\mathrm{P}=0.54)$, IL-8 $(\mathrm{P}=0.94)$, and TNF- $\alpha(\mathrm{P}=0.76)$.

\section{Valrubicin's effect on $P$. acnes- induced skin inflammation in vivo}

Valrubicin's effect on $P$. acnes-induced skin inflammation in vivo was tested by treating mouse ears, challenged by injection of $P$. acnes. Short term (1 day) topical valrubicin treatment demonstrated no reduction in ear thickness (Figure 2a); ear thickness in both valrubicin and vehicle treated mouse ears was increased approximately 2 -fold after 24 hrs. Long term (2 weeks) daily topical valrubicin treatment was tested in repeated experiments where mouse ears were injected with the same amount of $P$. acnes (Figure 2b) or 30\% fewer P. acnes (Figure 2c). No reduction in ear thickness was seen in valrubicin treated mouse ears compared with vehicle treated ears, at any time point during the 2 weeks. Ear thickness, in both the valrubicin and vehicle treated mouse ears, increased approximately 3 -fold (Figure 2b) and 2-fold (Figure 2c) after 24 hrs. Mouse ears treated with valrubicin alone, demonstrated no change in ear thickness during the 2 weeks. Repeated acetone-applications have previously been demonstrated, by our group, not to affect ear thickness. ${ }^{9}$ In a final experiment, to facilitate the ability of valrubicin to locate directly into the site of inflammation, valrubicin was injected intra-dermally into the mouse ears (Figure 2d). No effect of valrubicin as compared with vehicle, on ear thickness, was observed.

Table 1. Valrubicin's antibacterial effect on P. acnes.

\begin{tabular}{|c|c|c|c|}
\hline Valrubicin concentration and formulation & 1.4.L1 & 12.1.L1 & 30.2.L1 \\
\hline $250 \mathrm{mg} / \mathrm{mL}$ in acetone & $*$ & $*$ & $*$ \\
\hline $25 \mathrm{mg} / \mathrm{mL}$ in acetone/DMSO (1:10) & $*$ & $*$ & $*$ \\
\hline $5 \mu \mathrm{g} / \mathrm{mL}$ in acetone/sterile water $(1: 10,000)$ & $*$ & $*$ & $*$ \\
\hline $40 \mathrm{mg} / \mathrm{mL}\left(\right.$ Valstar $\left.^{\circledR}\right)$ in cremophor/ethanol (1:1) & $*$ & $*$ & $*$ \\
\hline $10 \mathrm{mg} / \mathrm{mL}\left(\right.$ Valstar $\left.^{\circledR}\right)$ in cremophor/ethanol/sterile water (1:1:4) & * & * & * \\
\hline $10 \mathrm{mg} / \mathrm{mL}$ in cream (1\% batch) & * & $*$ & $*$ \\
\hline $10 \mathrm{mg} / \mathrm{mL}$ in cream gel (1\% batch) & $*$ & $*$ & $*$ \\
\hline
\end{tabular}

(a)

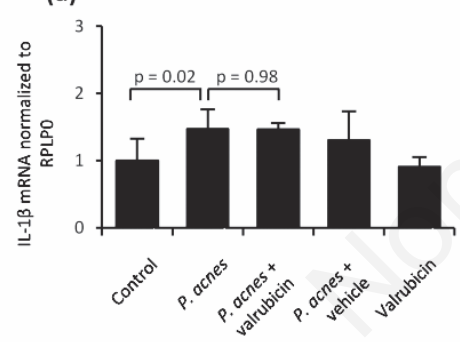

(d)

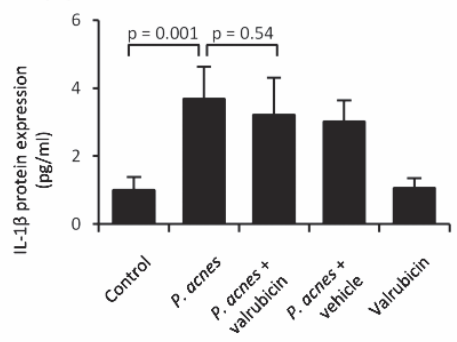

(b)

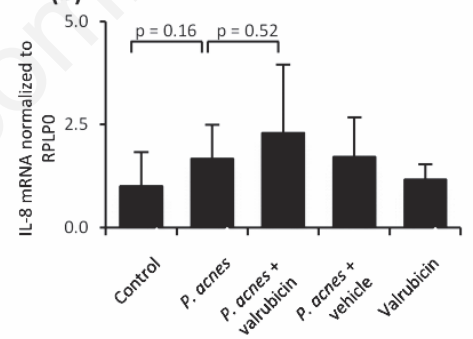

(e)

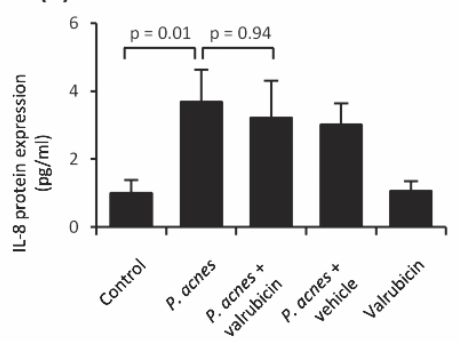

(c)

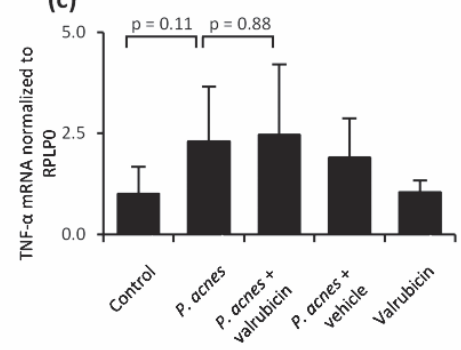

(f)

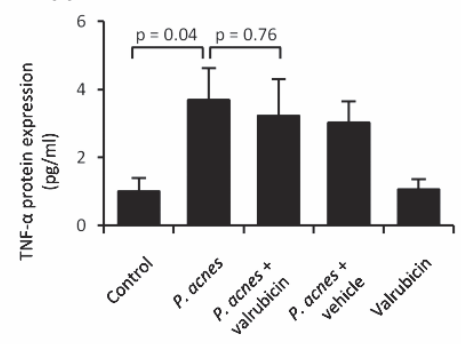

Figure 1. Valrubicin's effect on $P$. acnes-induced mRNA and protein expression levels of inflammatory cytokines by NHEKs. NHEKs from four healthy donors, were cultured in the presence of freshly prepared $P$. acnes. The effect of valrubicin on $P$. acnes-induced mRNA expression levels of IL-1 $\beta$ (a), IL-8 (b), and TNF- $\alpha$ (c) was evaluated after 2 hrs of stimulation. mRNA expression levels were normalized to the expression levels of the housekeeping gene, ribosomal protein large P0 (RPLP0) and to the untreated control (no P. acnes bacteria added). The effect of valrubicin on P. acnes-induced protein expression levels of IL-1 $\beta$ (d), IL-8 (e), and TNF- $\alpha$ (f) was evaluated after 12 hrs of stimulation. Protein expression levels were determined by ELISA and normalized to the untreated control (no $P$. acnes bacteria added). Values are presented as mean + standard deviation (NHEKs, $n=4$ donors, cultured in triplicate). 


\section{Discussion}

Several treatment modalities exist for acne, however, some may be associated with adverse side effects and therapeutic failure. ${ }^{1}$ Thus, research is focused on discovering new and improved treatments to expand the current treatment palette.

The role of $P$. acnes in the pathogenesis of acne has been discussed, as $P$. acnes is also a commensal of healthy skin. ${ }^{2}$ Recent findings, by multi-locus sequence typing (MLST), however, have shown that $P$. acnes can be divided into different strains associated with either moderate to severe acne, healthy skin or opportunistic infections. ${ }^{10,12}$ Nevertheless, the majority of acne treatments, currently available, are associated with anti-inflammatory effects and not necessarily antibacterial effects. Interestingly, prolonged antibiotic treatment, associated with high degree of $P$. acnes resistance, often alleviates acne lesions; a fact explained by anti-inflammatory effects of the antibiotics. ${ }^{15,16}$

Valrubicin did not demonstrate anti-inflammatory effects on primary keratinocytes co-cul- tured with $P$. acnes, as measured by mRNA and protein expression levels of IL-1 $\beta$, IL- 8 , and TNF- $\alpha$. These findings were surprising as we previously demonstrated that 2 hrs of valrubicin treatment significantly reduced mRNA expression levels of IL-1 $\beta$ and IL-6 in 12-Otetradecanoylphorbol 13-acetate (TPA) treated mouse ears, ${ }^{9}$ and because 2 hrs of valrubicin treatment demonstrated to significantly reduce mRNA expression levels of IL-1 $\beta$, IL-8 and TNF- $\alpha$ in stimulated keratinocytes and immune cells (unpublished results). Moreover, we previously demonstrated that 8 hrs and 24 hrs of valrubicin treatment significantly reduced protein expression levels of IL-1 $\beta$ and IL-6 in TPA treated mouse ears. ${ }^{9}$ Also, we previously reported that the employed concentration of valrubicin $(5.0 \mu \mathrm{g} / \mathrm{mL})$ was able to inhibit proliferation of NHEKs in cell culture. ${ }^{7}$ Why valrubicin reduces TPA-induced inflammation and not $P$. acnes-induced inflammation is unclear.

IL-1 $\beta$, IL- 8 and TNF- $\alpha$ are expressed in human acne lesions, ${ }^{17-20}$ and $P$. acnes has previously been demonstrated to stimulate secretion of these pro-inflammatory cytokines in keratinocytes. ${ }^{21-25}$ The fact that IL-1 $\beta$ is up-reg- ulated in acne skin ${ }^{17}$ has proposed beneficial effects of IL-1 $\beta$-targeted therapy which was recently shown to be the case, in patients suffering from auto-inflammatory syndromes including acne-lesions. ${ }^{26-28}$

Topical valrubicin treatment did not reduce $P$. acnes-induced ear inflammation following short and long term treatments. In a similar study, by our group, Hauge et al. induced both acute and chronic inflammation in the same mouse strain by stimulating mouse ears topically with TPA. ${ }^{9}$ In this study, topical valrubicin treatment significantly reduced TPA-induced ear inflammation in both the acute and the chronic model. In both studies, topical valrubicin was applied in equal amounts and concentrations. Again, why valrubicin reduces TPA-induced inflammation and not $P$. acnesinduced inflammation is unclear.

Previous studies have successfully demonstrated anti-inflammatory effects in the employed $P$. acnes injected ear-inflammation model. ${ }^{17,29}$ Similar numbers of $P$. acnes were injected, however different $P$. acnes strains were employed. These studies demonstrated a similar 2-4 fold increase in ear thickness upon $P$. acnes injection which then decreased upon (a)

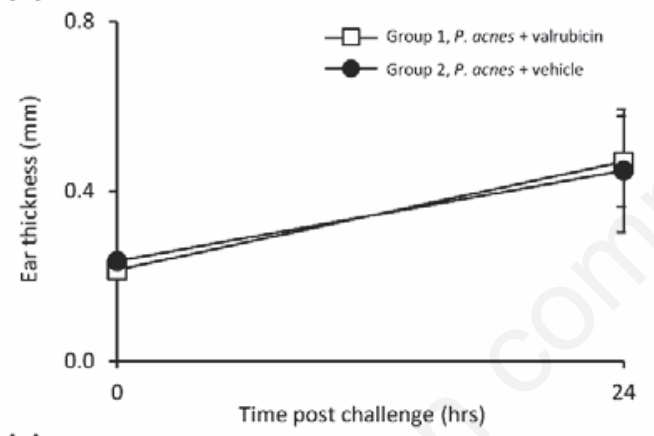

(c)

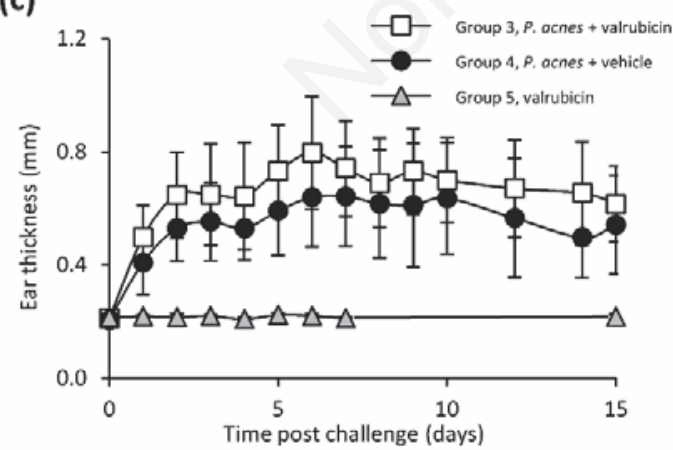

(b)

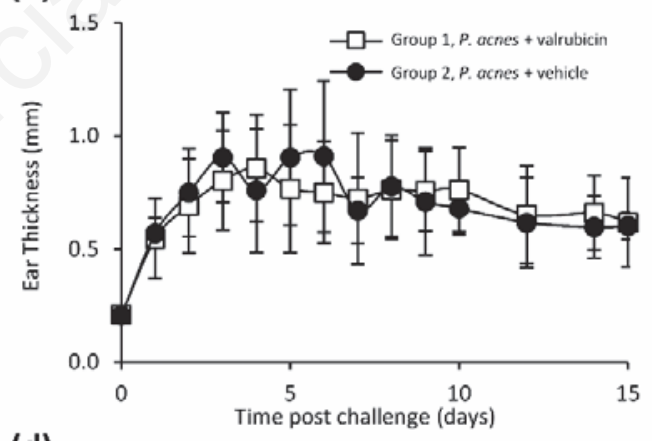

(d)

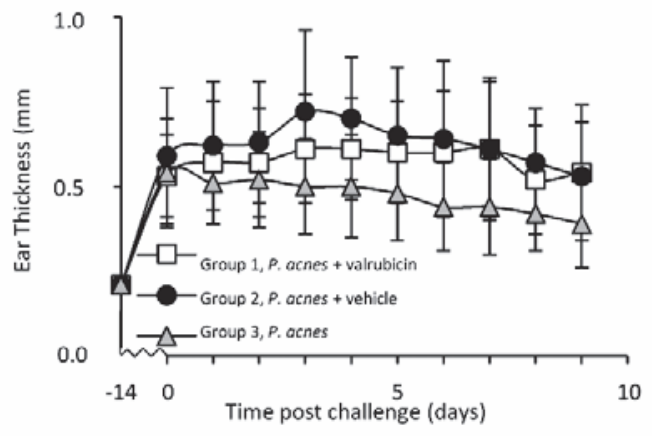

Figure 2. Effect of valrubicin treatment on P. acnes-induced ear inflammation. Ear inflammation was induced in mouse ears by challenging ears with intra-dermal injection of $15 \mu \mathrm{L}\left(9 \times 10^{7}\right.$; a and b) or $10 \mu \mathrm{L}\left(6 \times 10^{7}\right.$; c and d) freshly prepared $P$. acnes (clinical strain 1.4.L1). Short term (1 day) topical valrubicin treatment (a): 30 minutes post challenge, ears were treated topically with valrubicin (group $1, n=9)$ or vehicle (acetone, group $2, n=16)$. Long term ( 2 weeks) topical valrubicin treatment $(b$, c): 30 minutes post challenge and daily hereafter throughout the study, ears were treated topically with valrubicin group $1(n=7)$ and group 3 (n=8) or vehicle (acetone) group $2(n=4)$ and group $4(n=8)$. As control, an additional group of mouse ears (group 5, $n=8)$ was left unchallenged but treated daily with valrubicin throughout the study. Intra-dermal valrubicin treatment (d): 2 weeks post challenge, ears were treated daily for 3 days with central intra-dermal injections of valrubicin (Valstar $\left.{ }^{\circledR}\right)$ group $1 \quad(n=12)$ or vehicle (cremophor/ethanol [1:1]) group 2 $(n=11)$. As control, an additional group of challenged ears were left untreated group $3(n=9)$. Ear thickness was measured at indicated time points. Values are presented as mean \pm standard deviation. 
treatment. Decreased levels of IL-1 $\beta$, IL-8 and TNF- $\alpha$ in this model, upon treatment, have also been demonstrated. ${ }^{29}$

\section{Conclusions}

Taken together, valrubicin did not demonstrate antibacterial effects against $P$. acnes nor did it reduce $P$. acnes-induced inflammation in vitro and in vivo. Acne is, however, a multifactorial disease, and valrubicin may, despite the lack of antibacterial and anti-inflammatory effects, demonstrate beneficial effects on other aspects of the disease.

\section{References}

1. James WD. Clinical practice. Acne. N Engl J Med 2005;352:1463-72.

2. Gollnick H, Cunliffe W, Berson D, et al. Management of acne: a report from a global alliance to improve outcomes in acne. $\mathrm{J}$ Am Acad Dermatol 2003;49:S1-37.

3. Ayer J, Burrows N. Acne: more than skin deep. Postgrad Med J 2006;82:500-6.

4. Vowels BR, Yang S, Leyden JJ. Induction of proinflammatory cytokines by a soluble factor of propionibacterium acnes: implications for chronic inflammatory acne. Infect Immun 1995;63:3158-65.

5. Kuznetsov DD, Alsikafi NF, O'Connor RC, et al. Intravesical valrubicin in the treatment of carcinoma in situ of the bladder. Expert Opin Pharmacother 2001;2:100913.

6. Krishan A, Dutt $K$, Israel $M$, et al. Comparative effects of adriamycin and $n-$ trifluoroacetyladriamycin-14-valerate on cell kinetics, chromosomal damage, and macromolecular synthesis in vitro. Cancer Res 1981;41:2745-50.

7. Rosada C, Stenderup K, de Darkó E, et al. Valrubicin in a topical formulation treats psoriasis in a xenograft transplantation model. J Invest Dermatol 2010;130:455-63.

8. Andersen SM, Rosada C, Dagnaes-Hansen F, et al. Topical application of valrubicin has a beneficial effect on developing skin tumors. Carcinogenesis 2010;31:1483-90.

9. Hauge E, Christiansen H, Rosada C, et al.
Topical valrubicin application reduces skin inflammation in murine models. Br $\mathrm{J}$ Dermatol 2012;167:288-95.

10. Lomholt HB, Kilian M. Population genetic analysis of propionibacterium acnes identifies a subpopulation and epidemic clones associated with acne. PloS One 2010;5:e12277.

11. Bruggemann $\mathrm{H}$, Lomholt HB, Tettelin $\mathrm{H}$, et al. Crispr/cas loci of type ii propionibacterium acnes confer immunity against acquisition of mobile elements present in type i p. acnes. PloS One 2012;7:e34171.

12. Kilian M, Scholz CF, Lomholt HB. Multilocus sequence typing and phylogenetic analysis of propionibacterium acnes. J Clin Microbiol 2012;50:1158-65.

13. Ross JI, Snelling AM, Carnegie E, et al. Antibiotic-resistant acne: lessons from europe. Br J Dermatol 2003;148:467-78.

14. Kragballe K, Desjarlais L, Voorhees JJ. Leukotrienes b4, c4 and d4 stimulate DNA synthesis in cultured human epidermal keratinocytes. Br J Dermatol 1985;113:4352.

15. Esterly NB, Furey NL, Flanagan LE. The effect of antimicrobial agents on leukocyte chemotaxis. J Invest Dermatol 1978;70:515.

16. Webster GF, Leyden JJ, McGinley KJ, et al. Suppression of polymorphonuclear leukocyte chemotactic factor production in propionibacterium acnes by subminimal inhibitory concentrations of tetracycline, ampicillin, minocycline, and erythromycin. Antimicrob Agents Chemother 1982;21: 770-2.

17. Kistowska M, Gehrke S, Jankovic D, et al. Il-1beta drives inflammatory responses to propionibacterium acnes in vitro and in vivo. J Invest Dermatol 2014;134:677-85.

18. Ingham E, Eady EA, Goodwin CE, et al. Proinflammatory levels of interleukin-1 alphalike bioactivity are present in the majority of open comedones in acne vulgaris. $\mathrm{J}$ Invest Dermatol 1992;98:895-901.

19. Kang S, Cho S, Chung JH, et al. Inflammation and extracellular matrix degradation mediated by activated transcription factors nuclear factor-kappab and activator protein-1 in inflammatory acne lesions in vivo. Am J Pathol 2005;166:16919.

20. Trivedi NR, Gilliland KL, Zhao W, et al.
Gene array expression profiling in acne lesions reveals marked upregulation of genes involved in inflammation and matrix remodeling. J Invest Dermatol 2006;126:1071-9.

21. Akaza N, Akamatsu H, Kishi M, et al. Effects of propionibacterium acnes on various mrna expression levels in normal human epidermal keratinocytes in vitro. $\mathbf{J}$ Dermatol 2009;36:213-23.

22. Graham GM, Farrar MD, Cruse-Sawyer JE, et al. Proinflammatory cytokine production by human keratinocytes stimulated with propionibacterium acnes and p. Acnes groel. Br J Dermatol 2004;150:421-8.

23. Nagy I, Pivarcsi A, Koreck A, et al. Distinct strains of propionibacterium acnes induce selective human beta-defensin-2 and interleukin-8 expression in human keratinocytes through toll-like receptors. J Invest Dermatol 2005;124:931-8.

24. Akaza N, Akamatsu H, Kishi M, et al. Normal human epidermal keratinocytes react differently than hacat keratinocyte cell line on exposure to propionibacterium acnes. J Dermatol 2011;38:499-502.

25. Isard 0, Leveque M, Knol AC, et al. Antiinflammatory properties of a new undecylrhamnoside (aprc11) against p. Acnes. Arch Dermatol Res 2011;303:707-13.

26. Brenner M, Ruzicka T, Plewig G, et al. Targeted treatment of pyoderma gangrenosum in papa (pyogenic arthritis, pyoderma gangrenosum and acne) syndrome with the recombinant human interleukin1 receptor antagonist anakinra. Br J Dermatol 2009;161:1199-201.

27. Braun-Falco M, Kovnerystyy 0, Lohse P, et al. Pyoderma gangrenosum, acne, and suppurative hidradenitis (pash) - a new autoinflammatory syndrome distinct from papa syndrome. J Am Acad Dermatol 2012;66:409-15.

28. Wendling D, Prati C, Aubin F. Anakinra treatment of sapho syndrome: Short-term results of an open study. Annals of the rheumatic diseases 2012;71:1098-100.

29. Lee WR, Kim KH, An HJ, et al. The protective effects of melittin on propionibacterium acnes-induced inflammatory responses in vitro and in vivo. $\mathrm{J}$ Invest Dermatol 2014;134:1922-30. 